\title{
Long-term survival in elderly patients with a do-not-intubate order treated with noninvasive mechanical ventilation
}

This article was published in the following Dove Press journal:

International Journal of COPD

22 April 2011

Number of times this article has been viewed

Paolo Scarpazza'
Cristoforo Incorvaia ${ }^{2}$
Paolo Amboni ${ }^{3}$
Giuseppe di Franco'
Stefania Raschi'
Pierfranco Usai'
Monica Bernareggi'
Cristiano Bonacina'
Chiara Melacini'
Roberta Cattaneo'
Serena Bencini'
Chiara Pravettoni'
Gian Galeazzo
Riario-Sforza ${ }^{2}$
Gianni Passalacqua ${ }^{4}$
Walter Casali'
'Divisione di Broncopneumotisiologia,
Ospedale Civile,Vimercate, Italy;
${ }^{2}$ Pulmonary Rehabilitation, Istituti
Clinici di Perfezionamento, Milan,
Italy; ${ }^{3}$ Clinical Chemistry Laboratory,
Ospedali Riuniti, Bergamo, Italy;
${ }^{4}$ Allergy and Respiratory Diseases,
University Of Genoa, Genoa, Italy

Correspondence: Cristoforo Incorvaia Viale Molise, 69-20I 37 Milano, Italy

$\mathrm{Tel}+39025513852$

Fax +390257993315

Email cristoforo.incorvaia@gmail.com
Background: Noninvasive mechanical ventilation (NIMV) is an effective tool in treating patients with acute respiratory failure (ARF), since it reduces both the need for endotracheal intubation and the mortality in comparison with nonventilated patients. A particular issue is represented by the outcome of NIMV in patients referred to the emergency department for ARF and with a do-not-intubate (DNI) status because of advanced age or excessively critical conditions. This study evaluated long-term survival in a group of elderly patients with acute hypercapnic ARF who had a DNI order and who were successfully treated by NIMV.

Methods: The population consisted of 54 patients with a favorable outcome after NIMV for ARF. They were followed up for 3 years by regular control visits, with at least one visit every 4 months, or as needed according to the patient's condition. Of these, 31 continued NIMV at home and 23 were on long-term oxygen therapy (LTOT) alone.

Results: A total of 16 of the 52 patients had not survived at the 1-year follow-up, and another eight patients died during the 3 -year observation, with an overall mortality rate of $30.8 \%$ after 1 year and $46.2 \%$ after 3 years. Comparing patients who continued NIMV at home with those who were on LTOT alone, 9 of the 29 patients on home NIMV died ( 6 after 1 year and 3 after 3 years) and 15 of the 23 patients on LTOT alone died (10 after 1 year and 5 after 3 years).

Conclusion: These results show that elderly patients with ARF successfully treated by NIMV following a DNI order have a satisfactory long-term survival.

Keywords: COPD, acute respiratory failure, mortality rate, respiratory failure

\section{Introduction}

Patients suffering from severe chronic obstructive pulmonary disease (COPD) at an advanced stage are quite frequently affected by chronic or acute respiratory failure. ${ }^{1}$ The need to use ventilatory support is an indicator of a respiratory failure that influences survival. ${ }^{2}$ Noninvasive mechanical ventilation (NIMV), as showed by controlled trials and meta-analyses, is an effective tool in treating patients with respiratory failure. ${ }^{3-5}$ In fact, NIMV is able to reduce: 1) the need for endotracheal intubation (ETI), ${ }^{6}$ 2) mortality rates, and 3 ) the duration of intensive care unit (ICU) or hospital stays. ${ }^{7}$ These favorable outcomes have probably contributed to an increased use of NIMV in recent years. ${ }^{89}$ Nonetheless, there are special situations requiring further investigation to indicate NIMV as a first choice procedure. In fact, the impact of NIMV in chronic hypercapnic respiratory failure in severe COPD is controversial, as indicated by randomized controlled trials, particularly regarding survival. ${ }^{10}$ In addition, NIMV may have negative effects in acute respiratory failure, such as the delay in using ETI when the respiratory conditions require it. ${ }^{11,12}$ 
One of the particular aspects concerning the use of NIMV is represented by its outcome in patients who have a do-notintubate (DNI) status, which is dictated by their advanced age or by excessively critical and compromised conditions. We have previously demonstrated that elderly patients with acute respiratory failure due to COPD exacerbations (but also from restrictive thoracic disorders and multiorgan failure) and who had had a DNI order can be successfully treated by NIMV. ${ }^{13}$ This study addresses a 3-year follow-up of such patients.

\section{Materials and methods}

\section{Patients}

The study population has been previously described in detail. ${ }^{13}$ Briefly, 62 patients (30 males and 32 females; mean age $81 \pm 4.8$ years, range $79-91$ years) entered the study, in the semi-intensive Respiratory Medicine Unit of Vimercate Hospital (Italy). All patients were receiving long-term oxygen therapy (LTOT). Fifty patients had severe COPD, seven had restrictive thoracic disorders, and five had multiorgan failure. The inclusion criteria were: age $\geq 75$ years and a DNI order as defined by the unfavorable balance for ETI expressed by the emergency department physician (on the basis of advanced age and bad clinical status). The severity-of-illness classification was done by the Acute Physiology and Chronic Health Evaluation (APACHE) II, ${ }^{14}$ and the level of consciousness was established by the Glasgow Coma Score (GCS). ${ }^{15}$ Other considered parameters were $\mathrm{PaO}_{2} / \mathrm{FiO}_{2}$ (partial pressure of oxygen in arterial blood/ fraction of inspired oxygen), $\mathrm{PaCO}_{2}$ (partial pressure of carbon dioxide in arterial blood), $\mathrm{pH}$, respiratory rate, heart rate, and blood pressure.

A total of 54 patients were successfully treated with NIMV; two did not respond to NIMV and were intubated (one survived). The remaining six patients died after a mean of 9.9 days. Thus, the overall NIMV failure rate was $12.9 \%$.

The 54 patients with a favorable outcome entered the 3 -year follow-up phase of the study with regular control visits, carried out at least once every 4 months, or as needed according to the patient's conditions. Of these, 31 continued NIMV at home, based on the presence of chronic hypercapnic respiratory failure, and 23 remained on LTOT alone.

\section{Statistical analysis}

The number and characteristics of data required the use of both parametric and nonparametric tests. The student $t$-test (with the Welch variant) was used to analyze the two dependent variables (survival at 1 year and 3 years) according to the considered parameters. Nonlinear logistic regression was used to analyze the likelihood of survival at 1 year and 3 years according to the patient's age. The analysis of nonquantitative variables was performed by the Chi-square test. The statistical significance was set at a $P$ value $<0.05$.

\section{Results}

Out of the 54 patients, two (both belonging to the group continuing NIMV at home) were lost to follow-up, thus the analysis included 52 patients: 29 continuing NIMV and 23 on LTOT alone. A total of 16 of the 52 patients did not survive at the 1-year observation, none died during the 2 nd year, and another eight patients did not survive at the 3 -year observation, with an overall mortality rate of $30.8 \%$ after 1 year and $46.2 \%$ after 3 years (Figure 1 upper panel). Of the 52 patients, 41 (78.8\%) had severe COPD: $23 / 29(79 \%)$ in the NIMV group and 18/23 (78\%) in the LTOT group. The mortality rate in COPD patients was superimposable to the overall group: 12/41 (29.3\%) after 1 year and 19/41 (46.4\%) after 3 years. Comparing patients continuing NIMV at home with those on LTOT alone, 9 of the 29 patients continuing NIMV died (6 after 1 year and 3 after 3 years) and 15 of the 23 patients on LTOT alone died (10 after 1 year and 5 after 3 years) (Figure 1 lower panel). The mortality rates were 21\% after 1 year and $31 \%$ after 3 years in NIMV treated, while they were $43.5 \%$ after 1 year and $65.2 \%$ after 3 years in LTOT treated patients, respectively. None of these differences were statistically significant. Figure 2 shows the survival at 1 and 3 years of follow-up analyzed by logistic regression according to patient's age. Table 1 reports the dependence obtained from the considered parameters (the mean age, GCS,
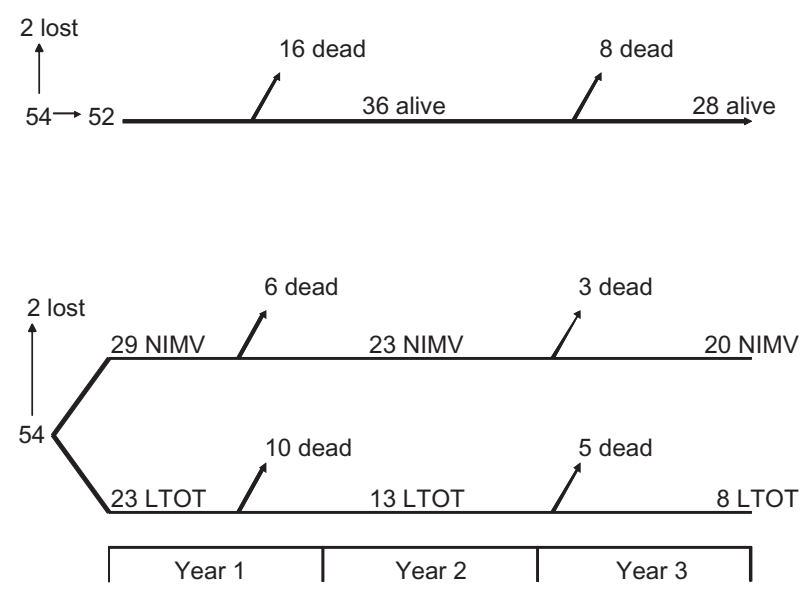

Figure I Flowchart describing the study patients in the overall population (upper panel) and in patients treated with NIMV or only by LTOT, respectively (lower panel). Abbreviations: NIMV, noninvasive mechanical ventilation; LTOT, long-term oxygen therapy. 
Logistic regression

Prob. ( $k$ years survival) $=$ YES

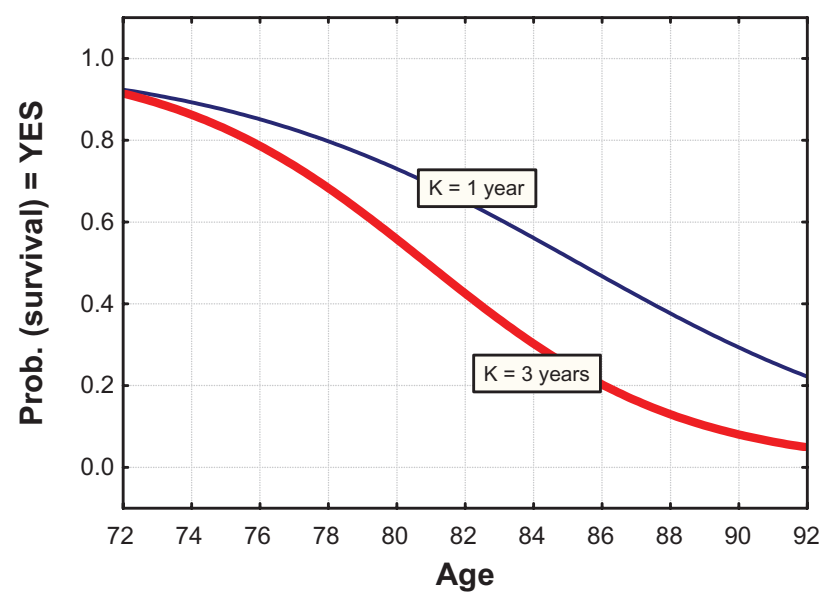

Figure 2 Survival after I and 3 years according to patient's age.

APACHE, blood gas parameters, inspiratory positive airway pressures (IPAPs) and expiratory positive airway pressures (EPAPs) set with NIMV. The dependence was significant only concerning age $(P<0.0001)$ and days of hospitalization in pulmonary units after 3 years $(P<0.0001)$. The mean days of hospitalization during the 3 -year follow-up were $9.6 \pm 11.6$. The mean numbers were $2.1 \pm 5.1$ after 1 year and $4.2 \pm 6.8$ after 3 years in NIMV-treated, while they were $1.7 \pm 4.9$ after 1 year and $1.6 \pm 4.3$ after 3 years in LTOTtreated patients, respectively. The analysis of nonquantitative variables by the Chi-square test showed no significant dependence for survival at 1 and 3 years.

\section{Discussion}

The development of acute respiratory failure (ARF) in patients with severe COPD or other respiratory diseases is a frequent cause of admission to emergency departments or to ICUs and is associated to significant mortality during the hospital stay and in the months following discharge. ${ }^{10,16}$ The long-term prognosis of these patients worsens if they need ventilatory support, either invasive or noninvasive. ${ }^{10,17}$ Notwithstanding, NIMV represented a major advance in treating patients with acute and chronic respiratory failure, with evidence of improved short- and long-term outcome. , $^{5,10,18}$ Predictors of unsuccessful NIMV include an arterial $\mathrm{pH}<7.25,{ }^{19}$ the presence of relevant comorbidities, ${ }^{20}$ low scores in the severity-of-illness classification, as assessed by APACHE II, and the level of consciousness by the GCS, ${ }^{21}$ and the lack of improvement in clinical and gas exchange measure within the first hour from starting NIMV. ${ }^{22}$

The first part of our study substantially confirmed these observation, in fact a low GCS, a high APACHE score at
Table I Parameters considered in analyzing survival

\begin{tabular}{|c|c|c|c|c|}
\hline \multirow{2}{*}{$\begin{array}{l}\text { Variable } \\
\text { (quantitative) }\end{array}$} & \multicolumn{2}{|c|}{ I year survival } & \multicolumn{2}{|c|}{3 years survival } \\
\hline & $\begin{array}{l}\text { Correlation } \\
\text { coefficient }\end{array}$ & $P$ & $\begin{array}{l}\text { Correlation } \\
\text { coefficient }\end{array}$ & $P$ \\
\hline Age & -0.38 & 0.005 & -0.49 & 0.000 \\
\hline GCS & -0.06 & 0.693 & 0.01 & 0.964 \\
\hline APACHE & 0.12 & 0.396 & 0.12 & 0.408 \\
\hline $\begin{array}{l}\text { Days of } \\
\text { hospitalization at } \\
\text { entrance }\end{array}$ & -0.09 & 0.539 & 0.04 & 0.761 \\
\hline $\mathrm{FiO}_{2}$ & -0.02 & $0.88 I$ & 0.16 & 0.245 \\
\hline $\mathrm{pO}_{2}$ & 0.01 & 0.953 & 0.08 & 0.573 \\
\hline $\mathrm{pCO}_{2}$ & 0.15 & 0.279 & 0.17 & 0.236 \\
\hline $\mathrm{pH}$ & 0.11 & 0.424 & 0.03 & 0.845 \\
\hline $\mathrm{HCO}_{3}$ & 0.19 & 0.188 & 0.11 & 0.421 \\
\hline $\mathrm{pO}_{2} / \mathrm{FiO}_{2}$ & 0.11 & 0.458 & -0.03 & 0.856 \\
\hline $\mathrm{FiO}_{2}$ at discharge & 0.20 & 0.148 & 0.19 & 0.189 \\
\hline $\mathrm{pO}_{2}$ at discharge & 0.12 & 0.393 & 0.02 & 0.912 \\
\hline $\mathrm{PO}_{2} / \mathrm{FiO}_{2}$ at discharge & -0.04 & 0.763 & -0.17 & 0.230 \\
\hline $\mathrm{PCO}_{2}$ at discharge & 0.16 & 0.258 & 0.18 & 0.200 \\
\hline $\mathrm{pH}$ at discharge & -0.18 & 0.198 & -0.12 & 0.392 \\
\hline $\mathrm{HCO}_{3}$ at discharge & 0.06 & 0.659 & 0.16 & 0.244 \\
\hline IPAP & 0.19 & 0.172 & 0.15 & 0.278 \\
\hline EPAP & 0.26 & 0.063 & 0.19 & 0.175 \\
\hline $\begin{array}{l}\text { Days of } \\
\text { hospitalization I year } \\
\text { in pulmonary units }\end{array}$ & -0.11 & 0.423 & -0.13 & 0.341 \\
\hline $\begin{array}{l}\text { Days of } \\
\text { hospitalization I year } \\
\text { in other units }\end{array}$ & -0.11 & 0.427 & -0.26 & 0.064 \\
\hline $\begin{array}{l}\text { Days of } \\
\text { hospitalization } \\
3 \text { years in } \\
\text { pulmonary units }\end{array}$ & 0.42 & 0.002 & 0.51 & 0.000 \\
\hline $\begin{array}{l}\text { Days of } \\
\text { hospitalization } 3 \text { years } \\
\text { in other units }\end{array}$ & 0.24 & 0.084 & 0.25 & 0.078 \\
\hline $\begin{array}{l}\text { Total days of } \\
\text { hospitalization }\end{array}$ & 0.23 & 0.094 & 0.22 & 0.111 \\
\hline
\end{tabular}

Abbreviations: APACHE, Acute Physiology and Chronic Health Evaluation; GCS, Glasgow Coma Score; EPAP, expiratory positive airway pressure; $\mathrm{FiO}_{2}$, fraction of inspired oxygen; IPAP, inspiratory positive airway pressure; $\mathrm{PCO}_{2}$, carbon dioxide partial pressure; $\mathrm{pO}_{2}$, partial pressure of oxygen.

admission, and a low $\mathrm{pH}$ both after 1 and 12 hours of NIMV were negative prognostic factors for response to treatment. ${ }^{13}$ However, the major aim of the study was to evaluate whether NIMV could be successful in patients who had received a DNI order, mainly because of an association of critical conditions and advanced age. Actually, the study included elderly patients (mean age of 81 years) with acute-on-chronic respiratory failure (all patients were on LTOT), and showed a low mortality rate (about $13 \%$ ), that is particularly favorable in this setting. In fact, previous studies reported older age as a predictor of NIMV failure in patients with ARF. ${ }^{19}$ Also, in our study, age was a critical factor, since the mean age of 
the NIMV-nonresponders was significantly higher compared with that of the responders ( 87.4 years versus 80.5 years). Regardless of age, our findings were more favorable than in previous studies on COPD patients with DNI status, which reported a mortality rate ranging from $34 \%$ to $43 \%$. $^{23-25}$

However, age is an important issue to be considered, because the increasing duration of life in the general population and the increasing life expectancy in COPD patients, mainly due to LTOT, make it common to find elder patients developing ARF. In these patients, the balance for ETI - as assessed by the emergency department physician - is often critical, leaving NIMV as the only treatment option. Indeed, to achieve a short-term low mortality rate with no evaluation of the long-term mortality should be of poor help in defining the actual role of NIMV in such patients.

This was the reason why we followed up the study patients. After 1 year, $69.2 \%$ of patients survived, and the survival rate was a rather satisfactory $53.8 \%$ after 3 years, this showing the importance of NIMV also in long-term survival of those patients. The survival rate we observed after 1 year is much higher than the rate of $16 \%$ reported by Bulow and Thorsager in their follow-up study of patients with a DNI. ${ }^{26}$ In our study, there was a clear difference in the mortality rate between the patients continuing NIMV at home (21\% after 1 year and $31 \%$ after 3 years) as compared with those treated with LTOT alone $(43.5 \%$ after 1 year and $65.2 \%$ after 3 years). These rates were not significantly different by statistical analysis, but this lack of significance is due to the quite low number of patients. On the other hand, our patients were not randomized to undergo NIMV or LTOT, but received the most appropriate treatment based on their condition, NIMV being given to patients with chronic hypercapnic respiratory failure. Another notable finding is the low number of days of hospitalization in our population, which further reinforces the role of NIMV by highlighting its apparent cost-effectiveness. As showed by a study conducted in Spain, 3 months of NIMV at home saved 63 days of hospitalization and cut costs for the health care financier by $50 \% .{ }^{27}$ The days of hospitalization are an essential measure for both costs and efficacy. In fact, in our study the number of days of hospitalization in pulmonary units at the 3-year observation was, together with age (which is quite obvious), the only significant factor associated with mortality $(P<0.0001)$.

In conclusion, this study shows that elderly patients with ARF successfully treated with NIMV following a DNI status have a satisfactory long-term survival, especially when they continue NIMV at home. This finding should encourage treatment by NIMV of patients with these characteristics.

\section{Disclosure}

The authors report no conflict of interest in this work.

\section{References}

1. Ambrosino N, Simonds A. The clinical management in extremely severe COPD. Respir Med. 2007;101:1613-1624.

2. Ai-Ping C, Lee KH, Lim TK. In hospital and 5-year mortality of patients treated in the ICU for acute exacerbations of COPD: a retrospective study. Chest. 2005;128:518-524.

3. Plant PK, Owen JL, Elliot MW. Early use of noninvasive ventilation for acute exacerbations of chronic obstructive pulmonary disease on general respiratory wards: a multicentre randomised controlled trial. Lancet. 2000;355:1931-1935.

4. Brochard L, Mancebo J, Elliott MW. Noninvasive ventilation for acute respiratory failure. Eur Respir J. 2002;19:712-721.

5. Lightowler JV, Wedzicka JA, Elliot MW, Ram FS. Non-invasive positive pressure ventilation to treat respiratory failure resulting from exacerbations of chronic obstructive pulmonary disease: Cochrane systematic review and meta-analysis. BMJ. 2003;326:185.

6. Antonelli M, Conti G, Rocco M, et al. A comparison of noninvasive positive-pressure ventilation and conventional mechanical ventilation in patients with acute respiratory failure. $N$ Engl J Med. 1998; 339:429-435.

7. Budweiser S, Jorres RA, Pfeifer M. Treatment of respiratory failure in COPD. Int J Chron Obstruct Pulmon Dis. 2008;3:605-618.

8. Carlucci A, Richard JC, Wysocki M, Lepage E, Brochard L. Noninvasive versus conventional mechanical ventilation. An epidemiologic survey. Am J Respir Crit Care Med. 2001;163:874-880.

9. Demoule A, Girou E, Richard JC, Taille S, Brochard L. Increased use of noninvasive ventilation in French intensive care units. Intensive Care Med. 2006;32:1747-1755.

10. Budweiser S, Jorres RA, Pfeifer M. Noninvasive home ventilation for chronic obstructive pulmonary disease: indications, utility and outcome. Curr Opin Pulm Med. 2008;14:128-134.

11. Jolliet P, Abajo B, Pasquina B, Chevrolet JC. Noninvasive pressure support ventilation in severe community acquired pneumonia. Intensive Care Med. 2001;27:812-821.

12. Esteban A, Frutos-Vivar F, Ferguson ND, et al. Noninvasive positive pressure ventilation for respiratory failure after extubation. $N$ Engl J Med. 2004;350:2452-2460.

13. Scarpazza P, Incorvaia C, di Franco G, et al. Effect of noninvasive mechanical ventilation in elderly patients with hypercapnic acuteon-chronic respiratory failure and a do-not-intubate order. Int J Chron Obstruct Pulmon Dis. 2008;3:797-801.

14. Knaus WA, Draper EA, Wagner DP, Zimmerman JE. APACHE II: a severity of disease classification system. Crit Care Med. 1985;13:818-829.

15. Teasdale T, Jennet B. Assessment of coma and impaired consciousness: a practical scale. Lancet. 1974;2:81-84.

16. Connors AF Jr, Dawson NV, Thomas C, et al. Outcomes following acute exacerbation of severe chronic obstructive lung disease. The SUPPORT investigators (Study to Understand Prognoses and Preferences for Outcomes and Risks of Treatment). Am J Respir Crit Care Med. 1996;154:959-967.

17. Chu CM, Chan VL, Lin AW, et al. Readmission rates and life threatening events in COPD survivors treated with non-invasive ventilation for acute hypercapnic respiratory failure. Thorax. 2004;59: $1020-1025$

18. American College of Chest Physicians. A consensus conference report. Clinical indications for non-invasive positive pressure ventilation in chronic respiratory failure due to restrictive lung disease, COPD, and nocturnal hypoventilation. Chest. 1999;116:521-534. 
19. Antonelli M, Conti G, Moro ML, et al. Predictors of failure of noninvasive positive pressure ventilation in patients with acute hypoxemic respiratory failure: a multicenter study. Intensive Care Med. 2001;27:1718-1728.

20. Nava S, Ceriana P. Causes of failure of noninvasive mechanical ventilation. Respir Care. 2004;49:295-303.

21. Confalonieri M, Garuti G, Cattaruzza MS, et al. A chart of failure risk for noninvasive ventilation in patients with COPD exacerbation. Eur Respir J. 2005;25:1130-1131.

22. Garpestad E, Brennan J, Hill NS. Noninvasive ventilation for critical care. Chest. 2007;132:711-720.

23. Levy M, Tanios MA, Nelson D, et al. Outcomes of patients with the do-not-intubate orders treated with non-invasive ventilation. Crit Care Med. 2004;32:2002-2007.
24. Schettino G, Altobelli N, Kacmarek RM. Noninvasive positive pressure ventilation reverses acute respiratory failure in select "do-not-intubate" patients. Crit Care Med. 2005;3:1976-1982.

25. Fernandez R, Baigorri F, Artigas A. Noninvasive ventilation in patients with "do-not intubate" orders: medium-term efficacy depends critically on patient selection. Intensive Care Med. 2007;33: $350-354$.

26. Bulow HH, Thorsager B. Non invasive ventilation in do-not-intubate patients: five-year follow-up in a two-year prospective, consecutive cohort study Acta Anaesthesiol Scand. 2009;53:1153-1157.

27. Lujan M, Moreno A, Veigas C, et al. Non-invasive home mechanical ventilation: effectiveness and efficiency of an outpatient initiation protocol compared with the standard in-hospital model. Respir Med. 2007;101;1177-1182.

International Journal of COPD

\section{Publish your work in this journal}

The International Journal of COPD is an international, peer-reviewed journal of therapeutics and pharmacology focusing on concise rapid reporting of clinical studies and reviews in COPD. Special focus is given to the pathophysiological processes underlying the disease, intervention programs, patient focused education, and self management protocols.

\section{Dovepress}

This journal is indexed on PubMed Central, MedLine and CAS. The manuscript management system is completely online and includes a very quick and fair peer-review system, which is all easy to use. Visit http://www.dovepress.com/testimonials.php to read real quotes from published authors.

Submit your manuscript here: http://www.dovepress.com/international-journal-of-copd-journal 